\title{
Left ventricular wall motion in patients with Chagas's disease
}

\author{
K E HAMMERMEISTER, ^ TOMAS CAEIRO, $†$ EMILIO CRESPO $†$ HUGO PALMERO,$\dagger$ \\ DEREK G GIBSON $\ddagger$ \\ From the Seattle Veterans Administration Medical Center, University of Washington, Seattle, USA; †Hospital \\ Privado, Centro Medico de Cordoba, Cordoba, Argentina; and the $\ddagger$ Brompton Hospital, London
}

SUMmaRY The effect of early chronic Chagas's disease on the timing and extent of regional left ventricular wall motion was studied with a frame by frame analysis of left ventriculograms in nine patients and compared with those in 19 normal subjects. In all the patients there was hypokinesis or akinesis in the anteroapical region together with delay in the onset of inward movement. Hypokinesis of the proximal inferior segment was also present, but the time of onset of inward motion here was normal. These differences can be explained on the basis of regional asynchrony within the normal left ventricle, where anteroapical wall motion is delayed with respect to that elsewhere. Thus contraction of the diseased anteroapical segment starts against an appreciable pressure and so may be isometric, whereas the affected proximal inferior segment starts contracting earlier against a lower pressure and so is able to shorten.

No abnormalities of wall motion were seen during isovolumic relaxation despite segmental involvement, which is a distinctly different finding from that in patients with coronary artery disease. This may be due partly to the absence of incoordinate relaxation in Chagas's disease and partly to myocardial involvement by Chagas's disease in the mid-anterior segment. This is the site of rapid early diastolic wall thinning, which has been put forward as a major mechanism of normal rapid ventricular filling and whose premature activity causes disturbances in regional wall motion before mitral valve opening when relaxation is incoordinate. Thus quantitative analysis of both the timing and amplitude of wall motion indicates fundamental differences between Chagas's disease and coronary artery disease, when a less complex analysis would have shown a similar pattern of segmental dysfunction in both. Since the effect of the same pathological process on wall motion varies with the site of ventricular involvement, the importance of the disturbances seen in Chagas's disease becomes apparent only when the non-uniformity of normal left ventricular structure and function is taken into account.

Chronic Chagas's disease is an important cause of congestive heart failure, arrhythmia, and death in large areas of Central and South America. ${ }^{1}$ Pathological examination typically shows thinning and aneurysm formation at the apex of the left ventricle. ${ }^{1-3} \mathrm{Few}$ studies, however, have examined global and segmental left ventricular function during life, particularly before the onset of severe congestive heart failure. Of particular interest to us was whether the segmental dysfunction of Chagas's disease results in incoordination of contraction and relaxation, as occurs in other diseases with segmental ventricular dysfunction such as coronary artery disease.

Dr Palmero died recently.

Accepted for publication 26 July 1983.

\section{Patients and methods}

STUDY PATIENTS

Fifteen patients with seropositive (GuerreiroMachado test) chronic Chagas's disease underwent cardiac catheterisation and cineangiography. Nine patients (seven men and two women) had angiograms which were technically satisfactory for quantitation, and these form the basis of this report. The presenting symptoms were atypical chest pain (seven), anginal chest pain (one), and syncope (one). Two patients also complained of palpitations. Congestive heart failure symptoms were in New York Heart Association functional class I or II in all patients except one, whose symptoms were between class II and III. The car- 
diothoracic ratio ranged from 0.44 to 0.53 with a mean of 0.49. Electrocardiograms were abnormal in all patients, showing ventricular extrasystoles in four, sinus bradycardia in five, right bundle branch block in two, left bundle branch block in one (included because this does not produce an unusual wall motion pattern when assessed in the right anterior oblique projection: unpublished observation), left anterior hemiblock in three, and left ventricular hypertrophy in one.

\section{CONTROLS}

The data from the patients with Chagas's disease (study patients) were compared with those of 19 subjects without evident heart disease (controls) from the files of participants in the Veterans Administration Cooperative Study on valvular heart disease. Cardiac catheterisation was generally performed to evaluate chest pain, which was typical of angina in 10 controls and atypical in nine. All had normal resting electrocardiograms, normal ejection fractions $(\geqslant 0.50 \%)$, no segmental wall motion abnormalities on subjective analysis, and normal coronary arteriograms. No abnormalities were identified on $\mathbf{M}$ mode echocardiography in the 13 controls in whom this investigation was carried out. Exercise tests were performed in 12 controls and were unequivocally normal in nine and equivocal in one, whereas two were thought to have thallium-201 perfusion defects.

\section{CINEANGIOGRAPHY}

Left ventricular cineangiography was performed in the right anterior oblique projection at a frame rate of $30-60 / \mathrm{s}$. A sinus beat with good opacification not following a premature contraction was selected for analysis. The outline of radiographic contrast material in the left ventricle was digitised frame by frame for a full cardiac cycle using an $x-y$ digitising tablet interfaced to a Prime $\mathbf{4 0 0}$ computer. The cineangiograms were calibrated either by measurement of a $1 \mathrm{~cm}$ grid filmed at the centre of mass of the left ventricle or by measurement of the projected catheter diameter. Left ventricular volumes were calculated using the arealength method. 45 The left ventricular shape index was calculated as $4 \pi$ area/perimeter ${ }^{2} \cdot{ }^{6}$ This index has a value of 1 when the shape is a circle and becomes increasingly closer to zero as the left ventricular shape becomes elongated. The plots of ventricular volume and shape index against time were smoothed using a nine point polynomial approximation technique..$^{78}$

To assess the timing and extent of left ventricular wall motion, the technique of Gibson et al. ${ }^{9}$ was used. Forty equally spaced points are defined on the end diastolic left ventricular circumference excluding the aortic valve plane. Lines are constructed from each point to the nearest point on the end systolic outline and are numbered $1-40$ beginning with the point defining the inferior side of the aortic valve adjacent to the mitral valve. Along each of these lines the cavity silhouette position for each cine frame was defined in millimetres from the end diastolic position. These curves of cavity position against time were smoothed using a three point moving average. A plot of cavity silhouette position against time for line 30 (midanterior wall) from one of the controls is shown in Fig 1. The onset of inward motion was defined as the earliest point in systole where the slope was $\geqslant 1.0 \mathrm{~cm} / \mathrm{s}$ and persisted for $\geqslant 100 \mathrm{~ms}$. The extent of inward motion was defined as the maximum inward excursion. The isovolumic relaxation period was defined as the period between the time of end systolic (minimum) volume from the smoothed volume curve and mitral valve opening as judged by the first appearance of unopacified blood on the ventricular angiogram. The time of onset of inward motion and the time of peak inward motion were expressed as the time from the first maximum volume on the smoothed volume curve (first vertical on Fig. 1).

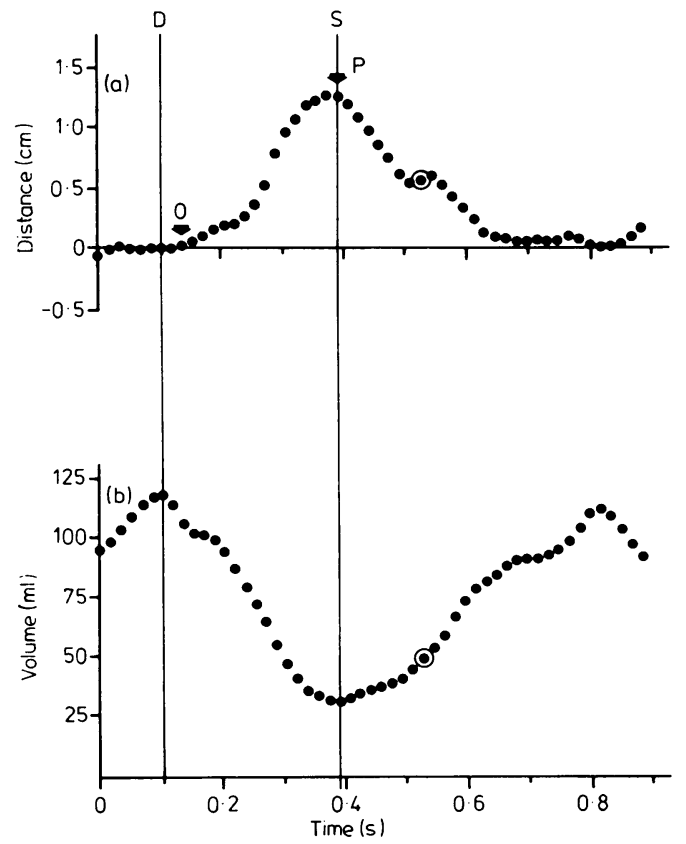

Fig. 1 (a) shows plot of displacement in relation to time of a point on the circumference of the left ventricle of a control. For comparison (b) shows a plot of left ventricular volume from the same beat. Each point is from a single cine frame. The two vertical lines indicate end diastolic $(D)$ and end systolic $(S)$ volumes. The two arrows indicate time of onset of systolic motion $(O)$ and time of peak systolic motion $(P)$. The circled point is the first frame showing unopacified blood in the left ventricle-that is, the end of the isovolumic relaxation period. 


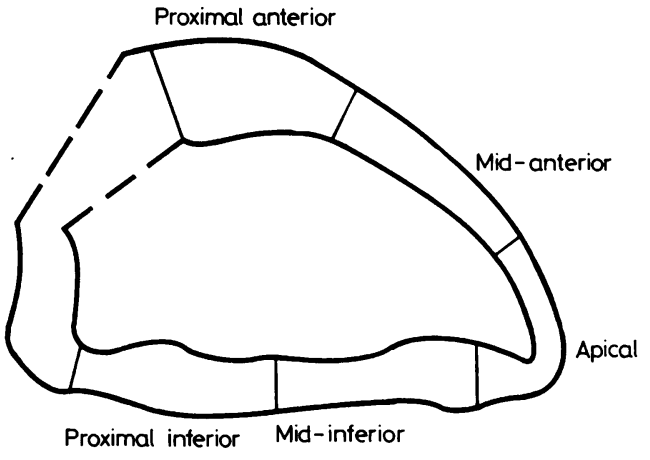

Fig. 2 End diastolic and end systolic silhouettes of the left ventricle from the right anterior oblique cineangiogram have been plotted showing the location of the five segments used in the wall motion analyses.

The data were averaged for the five standard segments in the right anterior oblique view: lines 6-12 for the proximal inferior segment, $13-18$ for the midinferior, $19-25$ for the apical, 26-32 for the midanterior, and 33-39 for the proximal anterior. The location of these segments is shown in Fig. 2.

The differences in timing of onset of inward and outward motion and extent of motion between the controls and study patients and between segments were first tested with a two way analysis of variance. If there was an overall significant difference between the controls and the study patients, then Student's $t$ test for unpaired data, corrected for multiple comparisons by applying Bonferonni's inequality, was used to identify the segments with the most significant differences.

\section{Results}

Selective coronary angiography was normal in all the study patients. Left ventricular end diastolic pressure

Table 1 Comparison of angiographic measurements of left vertricular function and wall motion between nine patients with Chagas's disease (study patients) and 19 normal subjects (controls). Figures are means \pm 1 standard deviation

\begin{tabular}{|c|c|c|c|}
\hline Measurement & $\begin{array}{l}\text { Study } \\
\text { patients }\end{array}$ & Controls & $\begin{array}{l}\text { Significance } \\
\text { of } \\
\text { difference }\end{array}$ \\
\hline \multirow{3}{*}{$\begin{array}{l}\text { End diastolic volume }(\mathrm{ml}) \\
\text { End systolic volume (ml) } \\
\text { Ejection fraction } \\
\text { Peak left ventricular ejection } \\
\text { rate (ml/s) } \\
\text { Peak left ventricular filling } \\
\text { rate (ml/s) } \\
\text { Diastolic shape index } \\
\text { Systolic shape index } \\
\text { \% Change in shape index } \\
\text { Heart rate (beats/min) }\end{array}$} & $\begin{array}{c}127 \pm 45 \\
55 \pm 25 \\
0.57 \pm 0.66\end{array}$ & $\begin{array}{c}152 \pm 34 \\
52 \pm 16 \\
0.66 \pm 0.07\end{array}$ & $\begin{array}{l}\text { NS } \\
\text { NS } \\
p<0.02\end{array}$ \\
\hline & $398 \pm 130$ & $443 \pm 116$ & NS \\
\hline & $\begin{array}{c}364 \pm 121 \\
0.84 \pm 0.05 \\
0.72 \pm 0.07 \\
15 \pm 5.1 \\
85 \pm 12\end{array}$ & $\begin{array}{c}473 \pm 180 \\
0.86 \pm 0.03 \\
0.71 \pm 0.4 \\
17 \pm 3.2 \\
65 \pm 17\end{array}$ & $\begin{array}{l}\text { NS } \\
\text { NS } \\
\text { NS } \\
\text { NS } \\
\mathrm{p}<0.01\end{array}$ \\
\hline
\end{tabular}

$\star$ Unpaired $t$ test.

NS = not statistically significant $(p>0.05)$.

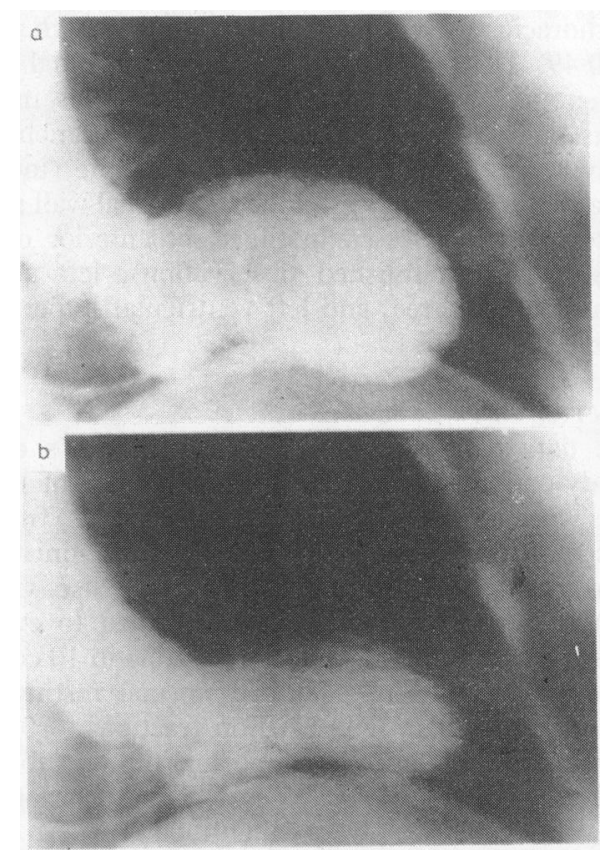

Fig. 3 End diastolic (a) and end systolic (b) frames from the right anterior oblique cineangiogram of $a$ patient with Chagas's disease showing the characteristic anterior-apical hypokinesis.

before angiography ranged from 8 to $28 \mathrm{~mm} \mathrm{Hg}$ with a mean of $14 \mathrm{~mm} \mathrm{Hg}$. The left ventricular angiograms showed anterior-apical hypokinesis or akinesis in all patients (Fig. 3). Table 1 shows the quantitative angiographic data. Left ventricular end diastolic and end systolic volumes were within the normal range. Ejection fraction (stroke volume divided by end diastolic volume) was, however, modestly but significantly reduced. The peak ejection rate was normal. The peak filling rate was reduced to about $84 \%$ of normal, but the difference was not statistically significant. The left ventricular shape during diastole and systole was normal, a finding consistent with the normal end diastolic volume and only a minimal reduction in ejection fraction. ${ }^{6}$

Visual displays of wall motion for each of the 40 points about the ventricular circumference from a patient with typical Chagas's disease are shown in Figs. 4 and 5. Table 2 shows the extent of systolic inward motion for each of the five ventricular segments in the study patients compared with that in the controls. The two way analysis of variance showed that there was both a significant difference in wall motion between the study patients and the controls $(\mathrm{F}=33.44, \mathrm{df}=1$ and $130 ; \mathrm{p}<0.001)$ and significantly non-uniform motion between segments $(F=8.56$, $\mathrm{df}=4$ and $130 ; \mathrm{p}<0.001)$. The greatest reduction in systolic inward motion was in the apical segment, but 


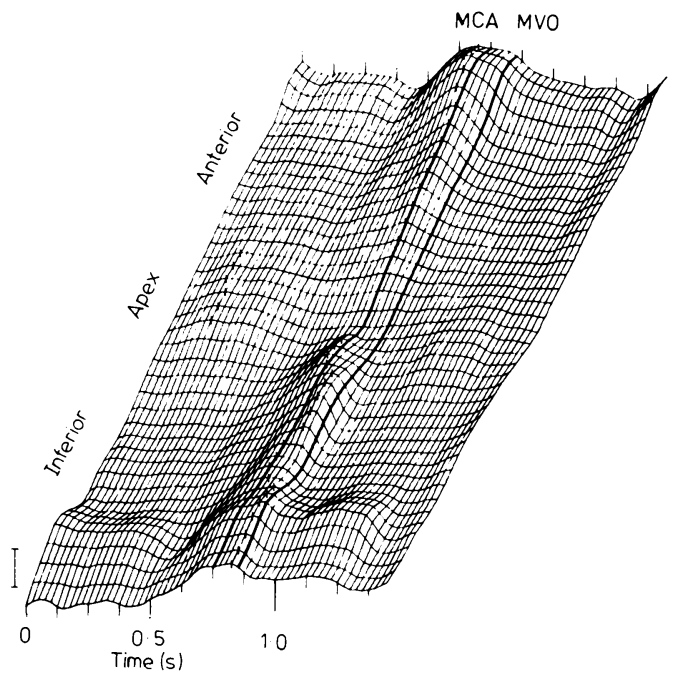

Fig. 4 Display of wall motion in relation to time from a patient with typical Chagas's disease. Each of the plots of displacement in relation to time of 40 points about the circumference of the left ventricle (see Fig. 1 for one of these plots from a control) have been placed one above another and offset to give a visual display of wall motion. Upward motion represents inward wall motion. The approximately vertical lines represent the time of each cine frame. The heavier lines indicate the time of minimum cavity area (MCA) and mitral valve opening (MVO). Decreased inward motion of the distal anterior wall and apex is readily apparent, but no wall motion abnormalities during isovolumic relaxation (MCA to MVO) are seen.

the proximal inferior segment also showed significantly abnormal motion in the study patients. In the controls the mid-anterior segment showed significantly less

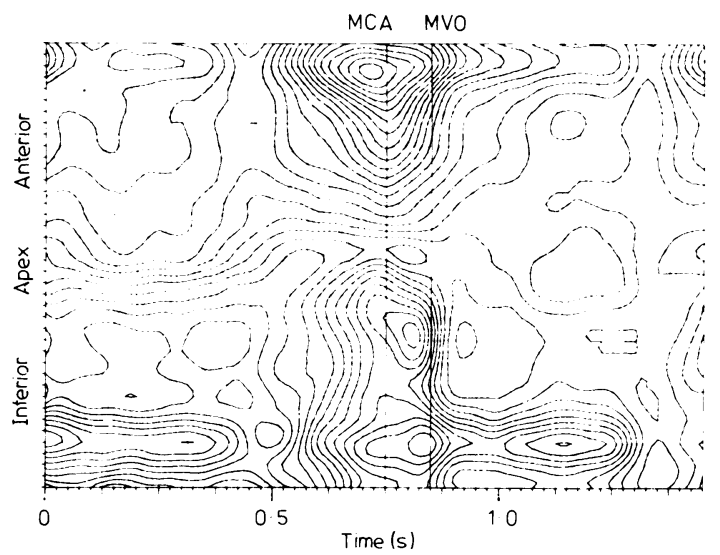

Fig. 5 An isocontour display of the data from the same patient as in Fig. 4. Each contour line represents $1 \mathrm{~mm}$ of inward or outward motion. Again the impaired inward motion in the apical-anterior region is noted, but isovolumic relaxation period motion is not abnormal. MCA, minimum cavity area; MVO, mitral valve opening.
Table 2 Comparison of extent of inward motion (cm) between 19 controls and nine patients with Chagas's disease. Figures are means \pm 1 standard deviation

\begin{tabular}{llll}
\hline Segment & Controls & $\begin{array}{l}\text { Study } \\
\text { patients }\end{array}$ & $\begin{array}{l}\text { Significance } \\
\text { of difference }\end{array}$ \\
\hline Proximal anterior & $1.24 \pm 0.30$ & $1.13 \pm 0.20$ & NS \\
Mid-anterior & $0.85 \pm 0.25$ & $0.61 \pm 0.23$ & NS \\
Apical & $1 \cdot 11 \pm 0.39$ & $0.53 \pm 0.23$ & $\mathrm{p}<0.005$ \\
Mid-inferior & $1.15 \pm 0.30$ & $0.93 \pm 0.21$ & NS \\
Proximal inferior & $1.14 \pm 0.36$ & $0.75 \pm 0.20$ & $\mathrm{p}=0.03$. \\
\hline
\end{tabular}

$\star$ Unpaired $t$ test.

NS $=$ not significant $(p>0.05)$

motion than the other segments (unpublished observation).

Table 3 shows timing of onset of inward motion for the two groups. The two way analysis of variance confirms that the onset of inward motion was not uniform between segments $(\mathrm{F}=15 \cdot 74, \mathrm{df}=4$ and 130 ; $\mathrm{p}<0.001)$. In the controls the mid-anterior segment was delayed by about $30 \mathrm{~ms}$ and the apical segment by about 70 ms. The onset of inward motion was significantly different between the study patients and the controls $(F=15.01, d f=1$ and $130 ; p<0.001)$. In the mid-anterior and apical segments, there was a pronounced additional delay of about $80 \mathrm{~ms}$ in the study patients compared with that in comparable segments in the controls.

As shown in Table 4, the time of peak inward motion in the study patients was delayed by $50-90 \mathrm{~ms}$ compared with that in the controls. Although none of

Table 3 Comparison of time of onset of inward motion ( $m s$ after maximum smoothed volume) between 19 normal subjects (controls) and nine patients with Chagas's disease (study patients). Figures are means \pm 1 standard deviation

\begin{tabular}{lrcl}
\hline Segment & Controls & $\begin{array}{l}\text { Study } \\
\text { patients }\end{array}$ & $\begin{array}{l}\text { Significance } \\
\text { of difference }\end{array}$ \\
\hline Proximal anterior & $27 \pm 28$ & $49 \pm 59$ & NS \\
Mid-anterior & $57 \pm 44$ & $136 \pm 64$ & $\mathrm{p}<0.005$ \\
Apical & $102 \pm 62$ & $182 \pm 78$ & $\mathrm{p}=0.03$ \\
Mid-inferior & $38 \pm 47$ & $41 \pm 92$ & $\mathrm{NS}$ \\
Proximal inferior & $28 \pm 35$ & $38 \pm 75$ & $\mathrm{NS}$ \\
\hline
\end{tabular}

$\star$ Unpaired $t$ test.

$\mathrm{NS}=$ not significant $(p>0-05)$.

Table 4 Comparison of time of peak inward motion ( $m s$ after maximum smoothed volume) between 19 normal subjects (controls) and nine patients with Chagas's disease (study patients). Figures are means \pm 1 standard deviation

\begin{tabular}{llll}
\hline Segment & Controls & $\begin{array}{l}\text { Study } \\
\text { patients }\end{array}$ & $\begin{array}{l}\text { Significance } \\
\text { of difference }\end{array}$ \\
\hline Proximal anterior & $376 \pm 64$ & $452 \pm 126$ & NS \\
Mid-anterior & $396 \pm 64$ & $487 \pm 125$ & NS \\
Apical & $405 \pm 63$ & $495 \pm 142$ & NS \\
Mid-inferior & $405 \pm 77$ & $455 \pm 109$ & NS \\
Proximal inferior & $426 \pm 64$ & $481 \pm 133$ & NS \\
\hline
\end{tabular}

$\star$ Unpaired $t$ test.

NS $=$ not significant $(p>0.05)$ 
Table 5 Comparison of extent of motion (cm) during isovolumic relaxation between 19 normal subjects (controls) and nine patients with Chagas's disease (study patients). Figures are means \pm 1 standard deviation

\begin{tabular}{llll}
\hline Segment & Controls & $\begin{array}{l}\text { Study } \\
\text { patients }\end{array}$ & $\begin{array}{l}\text { Significance } \\
\text { of difference }\end{array}$ \\
\hline Proximal anterior & $0.29 \pm 0.17$ & $0.30 \pm 0.13$ & NS \\
Mid-anterior & $0.25 \pm 0.16$ & $0.18 \pm 0.13$ & NS \\
Apical & $0.22 \pm 0.25$ & $0.10 \pm 0.14$ & NS \\
Mid-inferior & $0.24 \pm 0.17$ & $0.24 \pm 0.16$ & NS \\
Proximal inferior & $0.02 \pm 0.15$ & $0.12 \pm 0.09$ & NS \\
\hline
\end{tabular}

$\star$ Unpaired $t$ test.

$\mathrm{NS}=$ not significant $(p>0.05)$.

the segment by segment comparisons was different between the study patients and the controls, there was a significant overall difference between the two groups $(\mathrm{F}=19.83, \mathrm{df}=1$ and $130 ; \mathrm{p}<0.001)$. There was no significant difference in the timing of peak inward motion between segments, however $(F=0.91, \mathrm{df}=4$ and $130 ; p=0.46$ ).

Table 5 shows a comparison of the outward motion during the isovolumic relaxation period in the two groups. The controls showed $2-3 \mathrm{~mm}$ outward motion during this period in all segments except the proximal inferior segment. Isovolumic relaxation period wall motion in the study patients was similar overall to that in the controls $(\mathrm{F}=0.32, \mathrm{df}=1$ and 130 ; $p=0.57$ ). The two way analysis of variance confirms that there was a highly significant difference in the isovolumic relaxation motion between segments $(\mathrm{F}=7.88, \mathrm{df}=4$ and $130 ; \mathrm{p}<0.001)$.

\section{Discussion}

The angiographic abnormalities in this study were consistent with pathological reports, ${ }^{1210-12}$ results of previous angiographic studies, ${ }^{1-15}$ and observations of experimental Trypanosoma cruzi infections. ${ }^{3}$ The major effect of the disease on the amplitude of regional wall motion was in the anteroapical segments of the ventricle; although, as with previous studies, 121415 we were able to confirm reduced wall motion in the proximal inferior segment that was not apparent on subjective review of the films.

When the timing of wall motion is considered a notably different picture emerges, since the segments in which the overall amplitude is reduced do not correlate precisely with those in which the onset of motion is delayed. The proximal inferior segment, where amplitude was reduced to $66 \%$ of normal, showed no delay in the onset of inward motion at all. Although the amplitude of motion was reduced to $48 \%$ of normal at the apex and $72 \%$ of normal in the mid-anterior segment, the onset of inward motion was equally delayed in both ( 85 and $82 \mathrm{~ms}$ respectively).

Delay in the onset of inward motion does not neces- sarily imply delay in the onset of muscle fibre tension development. If activation were delayed or excitation-contraction coupling prolonged outward motion during isovolumic contraction and early ejection for a similar period would be expected. Such a pattern of motion is seen in patients with coronary artery disease, particularly along the inferior wall, when it is frequently associated with further inward motion during the period of isovolumic relaxation. 91617 In our patients, however, no outward wall movement was seen early in systole, nor was the duration of inward movement prolonged, suggesting that the onset of tension development had not been delayed but that contraction had initially been isometric. This is likely to have resulted from fibrous replacement of muscle, so that local tension development was not enough to lead to inward wall motion.

Our observations in subjects without heart disease suggest that involvement of the mid-anterior and apical segments would be particularly likely to cause such an abnormality. Normally, inward motion starts in the inferior and proximal anterior segments and is delayed by about 30 and $75 \mathrm{~ms}$ respectively in the mid-anterior and apical segments; inward motion in the mid-anterior and apical segments must, therefore, begin at a time when ventricular pressure is already appreciably raised, thus increasing the likelihood of isometric contraction early in systole if myocardial function is impaired. More advanced stages of the disease are likely to be associated with isometric contraction throughout systole (akinesis) and finally outward movement throughout systole (dyskinesis) as in coronary artery disease. ${ }^{17}$ Thus the same pathological process (destruction of myocardium by $T$ cruzi infection) leads to different patterns of wall motion in different segments of the ventricle. This varying response arises directly from the normal non-uniform pattern of ventricular wall motion.

A second finding of interest was the absence of notable disturbances of wall motion during isovolumic relaxation in patients with Chagas's disease such as are often present in patients with coronary artery disease who have similar segmental involvement. ${ }^{9}$ These disturbances manifest themselves as striking changes in left ventricular cavity shape at a time in the cardiac cycle when volume is constant. They have two components. There is a region of delayed or prolonged inward motion, often in the area supplied by a diseased coronary artery. At the same time there is compensatory outward movement elsewhere in the cavity to maintain a constant cavity volume. This outward movement almost invariably involves the mid-anterior wall, ${ }^{16}$ where it is associated with premature thinning of the myocardium before the mitral valve opens. ${ }^{18}$ It has frequently been described as the segmental early relaxation phenomenon, ${ }^{19-21}$ and has also been 
shown to occur to a lesser extent in other types of heart disease.

Neither component of the segmental early relaxation phenomenon occurs in Chagas's disease. We found no evidence of prolonged inward movement during isovolumic relaxation. The exact basis for this abnormality in coronary artery disease is not clear. In some patients, it represents the residual effect of delay in the onset of motion of the affected segment, inward movement starting approximately $80 \mathrm{~ms}$ late but proceeding normally thereafter; there is, of necessity, delay in the onset of relaxation. ${ }^{17}$ In the remainder inward wall movement starts normally but continues longer. Both abnormalities occur in the absence of angina or other evidence of acute ischaemia and are aggravated by giving nitrates or beta blocking drugs. ${ }^{22}$ It is unlikely, therefore, that they are directly caused by acute ischaemia but seem to be more closely related to the reperfusion abnormalities seen in experimental animals. ${ }^{23}$

The second component of the isovolumic shape change-early outward movement-also did not occur in Chagas's disease; the mid-anterior wall, the region of the left ventricular wall that is the most common site of early outward movement, is affected by Chagas's disease. Normal myocardium seems to be a prerequisite for early outward movement. We have suggested elsewhere ${ }^{24}$ that rapid thinning of the anterior wall is an autonomous process, normally occurring after mitral valve opening and constituting a mechanism by which rapid ventricular filling is brought about. This movement is accentuated in patients with non-rheumatic mitral regurgitation and may persist in mitral stenosis, even though filling rate is low with the result that inward wall movement may occur elsewhere in the cavity. ${ }^{25}$ Thus the involvement of the mid-anterior wall in Chagas's disease can be expected to have major effects on diastolic left ventricular function; in particular, it would be expected that isovolumic relaxation would be prolonged and peak filling rate reduced.

If the overall amplitude of left ventricular wall movement is considered in isolation the disturbances of regional left ventricular function seen in Chagas's disease might seem identical to those in coronary artery disease. When both amplitude and timing of wall movement are examined quantitatively, however, a clear distinction between the two conditions becomes apparent. Knowledge of the non-uniformity of normal left ventricular structure and function provides a coherent picture for explaining the abnormal and very characteristic pattern of wall movement in Chagas's disease.

We thank the investigators of the Veterans Administration Cooperative Study on Valvular Heart Disease, who allowed their cineangiograms to be analysed as a part of the control group; Dr David Hughs and $\mathrm{Mr}$ John VanDamme, who assisted in the data analyses; and Ms Barbara Buck, who assisted in preparation of the manuscript.

This research was supported by the US Veterans Administration, the British Heart Foundation, and Renault Argentina.

\section{References}

1 Laranja FS, Dias E, Nobrega G, Miranda A. Chagas' disease. A clinical, epidemiologic, and pathologic study. Circulation 1956; 14: 1035-60.

2 Puigb6 JJ, Valecillos R, Hirschhaut E, et al. Diagnosis of Chagas' cardiomyopathy. Non-invasive techniques. Postgrad Med F 1977; 53: 527-32.

3 Anselmi A, Moleiro F, Suárez R, Suárez JA, Ruesta V. Ventricular aneurysms in acute experimental Chagas' myocardiopathy. Chest 1971; 59: 654-8.

4 Dodge HT, Sandler H, Ballew DW, Lord JD Jr. The use of biplane angiocardiography for the measurement of left ventricular volume in man. Am Heart $\mathcal{F} 1960$; 60: 762-76.

5 Kennedy JW, Trenholme SE, Kasser IS. Left ventricular volume and mass from the single-plane cineangiocardiogram. A comparison of anteroposterior and right anterior oblique methods. Am Heart f 1970; 80: 343-52.

6 Gibson DG, Brown DJ. Continuous assessment of left ventricular shape in man. Br Heart $\mathcal{f}$ 1975; 37: 904-10.

7 Hammermeister KE, Brooks RC, Warbasse JR. The rate of change of left ventricular volume in man. I. Validation and peak systolic ejection rate in health and disease. Circulation 1974; 49: 729-38.

8 Brooks RC, VandeLinde VD, Hammermeister KE, Warbasse JR. Digital filtering of left ventricular heart volume and calculation of aortic valve blood flow. Comput Biomed Res 1971; 4: 340-54.

9 Gibson DG, Prewitt TA, Brown DJ. Analysis of left ventricular wall movement during isovolumic relaxation and its relation to coronary artery disease. $\mathrm{Br}$ Heart $\mathcal{F}$ 1976; 38: 1010-9.

10 Suarez JA, Puigb6 J, Nava Rhode J, Valero J, Gil Yepez C. Estudio anatomopatologico de 210 casos de miocardiopatia chagasica en Venezuela. Acta Med Venez 1968; 15: $320-30$.

11 Granzotti JA, Martin Neto JA, Gallo L, Manco JC, Rassi A, Amorim DS. Contribucao ao estudo do "aneurisma" da ponta na cardiopatia chagasica cronica. Arq Bras Cardiol 1974; 27: 477-87.

12 Acquatella $\mathrm{H}$, Schiller NB, Puigbó JJ, et al. M-mode and two-dimensional echocardiography in chronic Chagas' heart disease. Circulation 1980; 62: 787-99.

13 Puigbó JJ, Pisani F, Boccalandro I, Blanco P, Machado I, Valero JA. Estudio de la cardiopatia chagasica cronica. Empleo de la cinecoronariografia. Acta Med Venez 1968; 15: 339-50.

14 Crespo E, Palmero H, Caeiro T, Iosa D. Patron cineangiografica en la cardiopatia chagasica cronica. Medicina (B Aires) 1980; 40: 855-6.

15 Corrasco HA, Barboza JS, Inglessis G, Fuenmayor A, 
Mohna C. Left ventricular cineangiography in Chagas' disease: detection of early myocardial damage. Am Heart f 1982; 104: 595-602.

16 Greenbaum RA, Gibson DG. Regional non-uniformity of left ventricular wall movement in man. Br Heart $\mathcal{F} 1981$; 45: 29-34.

17 Gibson DG, Doran JH, Traill TA, Brown DJ. Abnormal left ventricular wall movement during early systole in patients with angina pectoris. Br Heart $\mathcal{F}$ 1978; 40: 758 66.

18 Gibson DG, Traill TA, Brown DJ. Changes in left ventricular free wall thickness in patients with ischaemic heart disease. Br Heart $\mathcal{f}$ 1977; 39: 1312-8.

19 Ruttley MS, Adams DF, Cohn PF, Abrams HL. Shape and volume changes during "isovolumetric relaxation" in normal and asynergic ventricles. Circulation 1974; 50: 306-16.

20 Altieri PI, Wilt SM, Leighton RF. Left ventricular wall motion during the isovolumic relaxation period. Circulation 1973; 48: 499-505.

21 Wilson CS, Krueger S, Forker AD, Weaver WF. Correlation between segmental early relaxation of the left ventricular wall and coronary occlusive disease. Am Heart $\mathcal{f}$ 1975; 89: 474-9.
22 Hall RJC, Doran J, Pusey C, McHaffie D, Gibson DG. The effect of nitroglycerin, beta blockade with acebutalol and isometric stress on incoordinate left ventricular function. Eur Heart $\mathcal{F}$ 1982; 3: 23-8.

23 Tyberg JV, Forrester JS, Wyatt HL, Goldner SJ, Parmley WW, Swan HJC. An analysis of segmental ischemic dysfunction utilizing the pressure-length loop. Circulation 1974; 49: 748-54.

24 Gibson DG, Greenbaum R, Marier DL, Brown DJ. Clinical significance of early diastolic changes on left ventricular wall thickness. Eur Heart $\mathcal{f}$ 1980; 1 (suppl A): 157-63.

25 Hui WKK, Lee PK, Chow JSF, Gibson DG. Analysis of regional left ventricular wall motion during diastole in mitral stenosis. $\mathrm{Br}$ Med $\mathcal{f}$ (in press).

Requests for reprints to Dr K E Hammermeister, Cardiology Section, Veterans Administration Medical Center, 1055 Clermnot Street, Denver, Colorado 80220, USA. 